\section{Right aortic arch associated with Kommerell's diverticulum and aberrant left subclavian artery: an unusual cause of dysphagia}

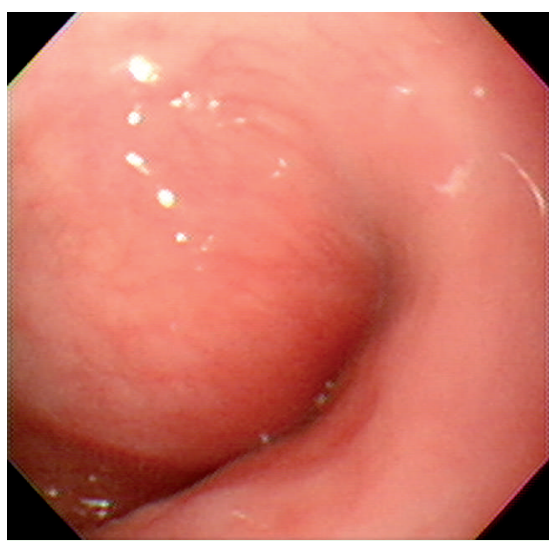

Fig. 1 Upper gastrointestinal endoscopic view showing extrinsic compression of the esophagus with significant narrowing of the esophageal lumen.

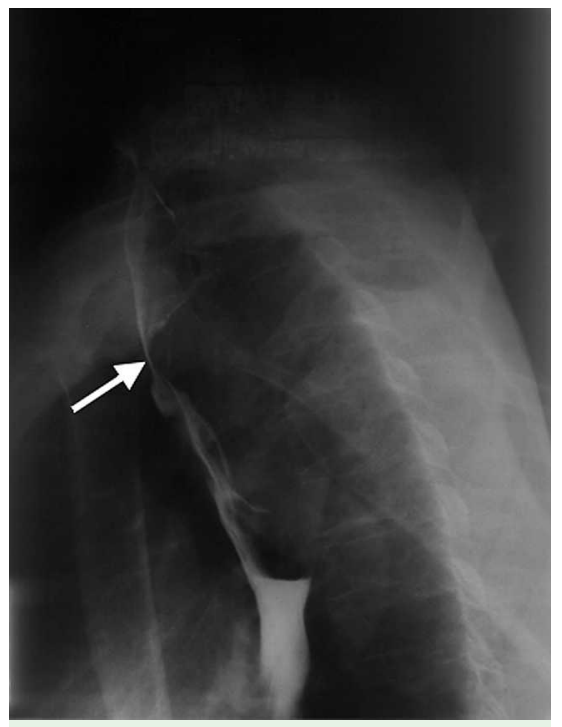

Fig. 2 Barium swallow showing posterior indentation of upper thoracic esophagus (arrow).

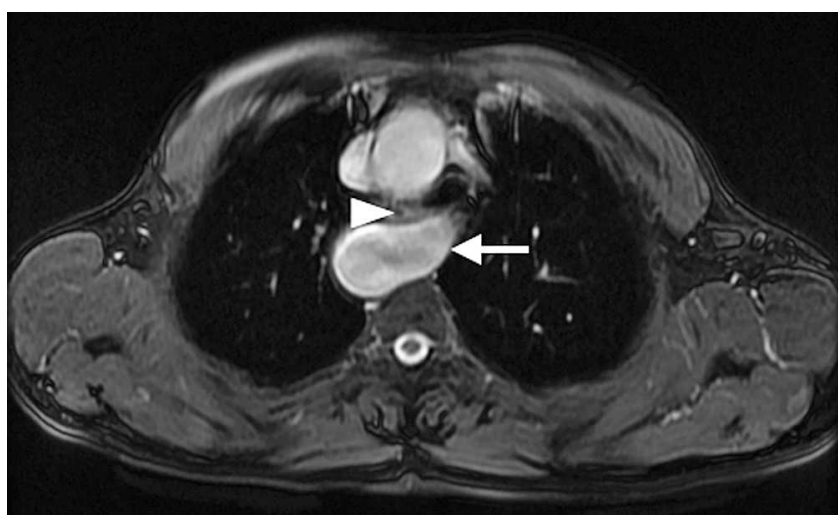

Fig. 3 Magnetic resonance (MR) imaging of the chest showing the esophagus (arrowhead) compressed by the Kommerell's diverticulum (arrow).

A 60-year-old man presented with a 2day history of fever, chill, and swelling of the left knee. There had been occasional dysphagia to solids during the previous 1 year. Aspirate from the left knee showed an elevated white cell count, but no bacteria. Chest radiograph showed widening of the upper mediastinum. Upper gastrointestinal endoscopy showed extrinsic compression of the upper thoracic esophagus with normal overlying mucosa (๑ Fig. 1).

Barium swallow demonstrated posterior indentation of the upper thoracic esophagus (๑ Fig. 2).

Computed tomography and magnetic resonance (MR) imaging of the chest re-
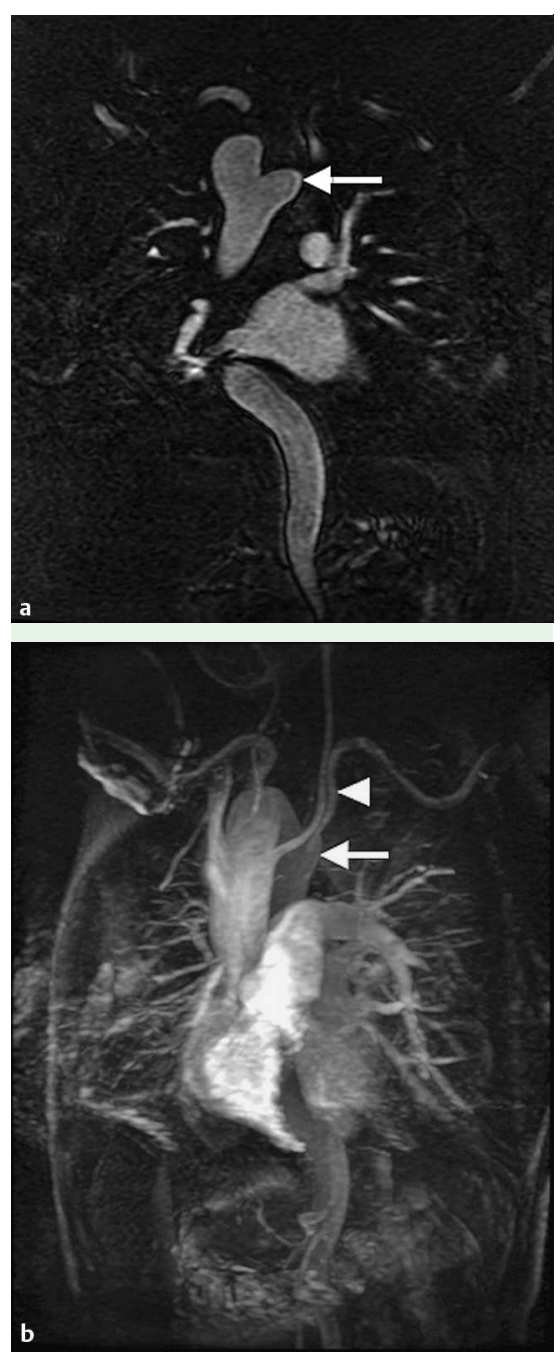

Fig. 4 a MR angiography showing Kommerell's diverticulum (arrow) from the descending thoracic aorta. $\mathbf{b}$ MR angiography showing Kommerell's diverticulum (arrow), from which the left subclavian artery (arrowhead) originates.

sic or extrinsic process. An unusual mechanical cause of dysphagia is extrinsic compression of the esophagus by anomalies of the aortic arch and its main branches. Right aortic arch with aberrant left subclavian artery is an anatomical anomaly of the aortic arch, occurring in about $0.05 \%$ of the general population [1]. Kommerell's diverticulum develops from a vestigial remnant of the distal, embryologic left aortic arch. The majority of patients with right-sided aortic arches with aberrant left subclavian arteries are asymptomatic. In adults, dysphagia is the most often reported symptom. Congenital heart defects occur in $5 \%$ of patients with this aortic root anomaly [2]. The diagnosis may initially be suggested by chest radiograph and barium swallow. Barium swallow demonstrates anterior 
displacement of the thoracic esophagus with a characteristic impression on the posterior esophagus. Angiography, CT, or MR imaging can be used to demonstrate any coexisting cardiac or vascular anomalies and to delineate the exact anatomy [3]. Treatment is conservative in asymptomatic patients, while surgery including resection of Kommerell's diverticulum and reconstruction of the aberrant subclavian artery is considered in those with persistent dysphagia or respiratory symptoms.

Endoscopy_UCTN_Code_CCL_1AB_2AC_3AF

Endoscopy_UCTN_Code_CCL_1AB_2AC_3AH
K.-C. Cheng ${ }^{1}$, H.-H. Chiu ${ }^{2}$, C.-C. Huang ${ }^{3}$

${ }^{1}$ Department of Orthopedics, Kuo General Hospital, Tainan, Taiwan

2 Department of Gastroenterology, Kuo General Hospital, Tainan, Taiwan

3 Department of Radiology, Kuo General Hospital, Tainan, Taiwan

\section{References}

1 Tsukube T, Ataka K, Sakata M et al. Surgical treatment of an aneurysm in the right aortic arch with aberrant left subclavian artery. Ann Thorac Surg 2001; 71: 1710- 1711

2 McKenna E, Kelly BE, Khan M. Dysphagia due to an aberrant left subclavian artery in a right-sided aortic arch. Ulster Med J 2001; 70: $64-66$

3 Cina C, Arena G, Bruin G, Clase CM. Kommerell's diverticulum and aneurysmal rightsided aortic arch: a case report and review of the literature. J Vasc Surg 2000; 32: $1208-1214$
Bibliography

DOI 10.1055/s-0029-1214695

Endoscopy 2009; 41: E157-E158

(c) Georg Thieme Verlag KG Stuttgart · New York . ISSN 0013-726X

Corresponding author

Hsin-Hui Chiu, Dr

Department of Gastroenterology

Kuo General Hospital

No 22. Sec 2, Ming-Sheng Road

Tainan 703

Taiwan

Fax: +886-6-2206600

shchiu@kgh.com.tw 